\title{
ERRATUM
}

\author{
M. Challet - V. Fourcassié - S. Blanco - R. Fournier • \\ G. Theraulaz $\cdot$ C. Jost
}

\section{A new test of random walks in heterogeneous environments}

Published online: 20 October 2005

C) Springer-Verlag 2005

\section{Naturwissenschaften (2005) 92:367-370}

Unfortunately, Fig. 1 has been printed with errors, hence the correct version is given here.

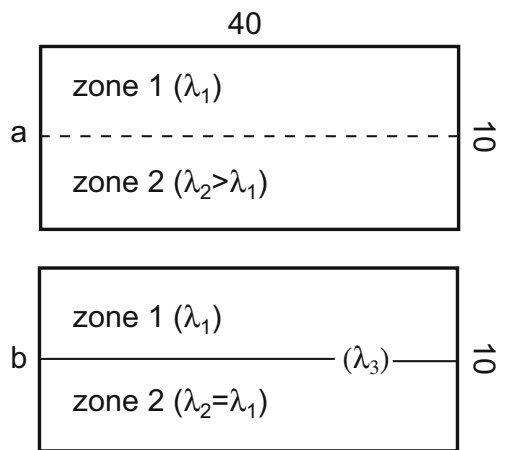

Fig. 1 The simulated trajectories are inscribed in a rectangular area $(40 \times 10$ arbitrary units) divided into two adjacent zones, each with its own mean move length $1 / \lambda$ and a symmetric distribution of turning angles around zero. a In the first condition, the mean distance travelled before changing direction is lower in zone 2 than in zone 1 $\left(1 / \lambda_{1}>1 / \lambda_{2}\right)$. b In the second condition, this distance is the same in the two zones, but the organisms have a tendency to follow the boundary between the two zones (straight line) and to leave it after travelling on average distance $1 / \lambda_{3}$

The online version of the original article can be found at http://dx. doi.org/10.1007/s00114-005-0001-1

M. Challet · V. Fourcassié $\cdot$ G. Theraulaz $\cdot$ C. Jost $(\bowtie)$

Centre de Recherches sur la Cognition Animale,

CNRS UMR 5169, Université Paul Sabatier,

Bât 4R3, 118 route de Narbonne,

31062 Toulouse Cedex 9, France

e-mail: jost@cict.fr

Tel.: +33-5-61556437

Fax: +33-5-61556154

S. Blanco - R. Fournier

Laboratoire d'énergétique, Université Paul Sabatier,

118 route de Narbonne,

31062 Toulouse Cedex 4, France 